\title{
Deleterious genetic variants in NOTCH1 are a major contributor to the incidence of non-syndromic Tetralogy of Fallot
}

Donna J. Page ${ }^{1}$, Matthieu J. Miossec ${ }^{2,3}$, Simon G. Williams ${ }^{1}$, Elisavet Fotiou ${ }^{1}$, Richard M. Monaghan ${ }^{1}$, Heather J. Cordell ${ }^{2}$, Louise Sutcliffe ${ }^{2}$, Ana Topf ${ }^{2}$, Mathieu Bourgey ${ }^{4,5}$, Guillaume Bourque $^{5}$, Robert Eveleigh ${ }^{5}$, Sally L. Dunwoodie ${ }^{6,7}$, David S. Winlaw ${ }^{8,9,10}$, Shoumo Bhattacharya $^{11}$, Jeroen Breckpot ${ }^{12}$, Koenraad Devriendt ${ }^{12}$, Marc Gewillig ${ }^{13}$, David Brook ${ }^{14}$, Kerry Setchfield ${ }^{14}$, Frances A. Bu'Lock ${ }^{15}$, John O'Sullivan ${ }^{16}$, Graham Stuart ${ }^{17}$, Connie Bezzina ${ }^{18}$, Barbara J.M. Mulder ${ }^{18}$, Alex V. Postma ${ }^{19,20}$, James R. Bentham ${ }^{21}$, Martin Baron ${ }^{22}$, Sanjeev S. Bhaskar ${ }^{23}$, Graeme C. Black ${ }^{23}$, William G. Newman ${ }^{23}$, Kathryn E. Hentges ${ }^{24}$, Mark Lathrop ${ }^{5}$, Mauro Santibanez-Koref ${ }^{2}$, Bernard D. Keavney ${ }^{1}$

1. Division of Cardiovascular Sciences, School of Medical Sciences, Faculty of Biology, Medicine, and Health, Manchester Academic Health Science Centre, University of Manchester, Manchester, M13 9PT, UK

2. Institute of Genetic Medicine, Newcastle University, Central Parkway, Newcastle-uponTyne, NE1 3BZ, UK

3. Center for Bioinformatics and Integrative Biology, Faculty of Biological Sciences, Universidad Andrés Bello, Santiago, Chile

4. Canadian Centre for Computational Genomics, Montréal, QC, Canada

5. McGill Genome Center, Montréal, QC, Canada

6. Chain Reaction Program in Congenital Heart Disease Research, Victor Chang Cardiac Research Institute, Sydney, NSW, Australia.

7. Faculties of Medicine and Science, University of New South Wales, Sydney, NSW, Australia

8. Heart Centre for Children, The Children's Hospital at Westmead, Sydney, NSW, Australia. 
9. School of Child and Adolescent Health, Sydney Medical School, University of Sydney, Australia.

10. Victor Chang Cardiac Research Institute, Australia

11. RDM Cardiovascular Medicine, Wellcome Centre for Human Genetics, University of Oxford, Oxford, OX3 7BN

12. Center for Human Genetics, Catholic University Leuven, Leuven, Belgium

13. Pediatric and Congenital Cardiology, UZ Leuven, Leuven, Belgium

14. School of Life Sciences, University of Nottingham, Queen's Medical Centre, Nottingham, NG7 2UH

15. Honorary Associate Professor in Congenital and Paediatric Cardiology, East Midlands, Congenital Heart Centre and University of Leicester, Glenfield Hospital, Leicester, LE3 9QP

16. MD, FRCPI, Adult Congenital and Paediatric Cardiac Unit, Freeman Hospital, Newcastle upon Tyne

17. University Hospitals Bristol NHS FoundationTrust, Bristol UK

18. Heart Center, Department of Clinical and Experimental Cardiology, Academic Medical Center, Amsterdam, the Netherlands

19. Department of Medical Biology, Academic Medical Center, Amsterdam, the Netherlands

20. Department of Clinical Genetics, Academic Medical Center, Amsterdam, the Netherlands 21. Department of Paediatric Cardiology, Yorkshire Heart Centre, Leeds, UK

22. Division of Molecular \& Cellular Function, School of Biological Sciences, Faculty of Biology Medicine, and Health, Manchester Academic Health Science Centre, University of Manchester, Manchester, M13 9PL, UK

23. Manchester Centre for Genomic Medicine, Saint Mary's Hospital, Oxford Rd, Manchester M13 9WL

24. Division of Evolution and Genomic Sciences, Faculty of Biology, Medicine and Health, Manchester Academic Health Science Centre, University of Manchester, Oxford Road, Manchester, M13 9PT, UK 
Correspondence should be addressed to Professor Bernard D. Keavney (email: bernard.keavney@manchester.ac.uk) and Dr. Donna J. Page (e-mail: donna.page@manchester.ac.uk)

\section{Abstract}

Aims: Familial recurrence studies provide strong evidence for a genetic component to the predisposition to sporadic, non-syndromic Tetralogy of Fallot (TOF), the most common cyanotic congenital heart disease (CHD) phenotype. Rare genetic variants have been identified as important contributors to the risk of $\mathrm{CHD}$, but relatively small numbers of TOF cases have been studied to date. Here, we use whole exome sequencing to assess the prevalence of rare, potentially deleterious variants in candidate genes previously associated with both syndromic and non-syndromic TOF, in the largest cohort of non-syndromic TOF patients reported to date.

Methods \& Results: 829 non-syndromic TOF patients underwent whole exome sequencing. A systematic review of the literature was conducted which revealed 77 genes in which mutations had been reported in patients with TOF. The presence of rare, deleterious variants in the 77 candidate genes was determined, defined by a minor allele frequency of $\leq$ 0.001 and scaled combined annotation-dependent depletion (CADD) score of $\geq 20$. We found a clustering of heterozygous rare, deleterious variants in NOTCH1 ( $\mathrm{P}=1.89 \mathrm{E}-15)$, DOCK6 ( $\mathrm{P}=2.93 \mathrm{E}-07)$, MYOM2 ( $\mathrm{P}=7.35 \mathrm{E}-05)$, TTC37 $(\mathrm{P}=0.016)$, MESP1 $(\mathrm{P}=0.024)$ and TBX1 $(\mathrm{P}=0.039)$, after correcting for multiple testing. NOTCH1 was most frequently found to harbour deleterious variants. Changes were observed in 49 patients $(6 \%$; $95 \%$ confidence interval $[\mathrm{Cl}]: 4.5 \%-7.8 \%)$ and included six truncating/frameshift variants and forty missense variants. Sanger sequencing of the unaffected parents of thirteen cases identified five de novo variants. Variants were not confined to a single functional domain of the NOTCH1 protein but significant clustering of variants was evident in the EGF-like repeats ( $P=0.018)$. 
Three NOTCH1 missense variants (p.G200R, p.C607Y and de novo p.N1875S) were subjected to functional evaluation and showed a reduction in Jagged1 ligand-induced NOTCH signalling. p.C607Y, which exhibited the most significant reduction in signalling, also perturbed S1 cleavage of the NOTCH1 receptor in the Golgi.

Conclusion: The NOTCH1 locus is a frequent site of genetic variants predisposing to nonsyndromic TOF with $6 \%$ of patients exhibiting rare, deleterious variants. Our data supports the polygenic origin of TOF and suggests larger studies may identify additional loci.

Keywords: Congenital heart disease; Tetralogy of Fallot; whole exome sequencing; $\mathrm{NOTCH} 1$

\section{Introduction}

Congenital heart disease (CHD) is the most common type of birth defect, affecting 8/1000 live births (1). CHD covers a large spectrum of heterogeneous cardiovascular phenotypes that range from single, localised defects to more complex structural abnormalities. Tetralogy of Fallot (TOF) is the most common complex, cyanotic CHD with a prevalence of $1 / 3000$ births $(1,2)$. TOF is considered a malformation of the cardiac outflow tract which comprises four specific structural characteristics postnatally; a ventricular septal defect (VSD), anterocephalad deviation of the outflow septum with resultant overriding of the aorta, variable obstruction of the right ventricular outflow tract (pulmonary stenosis) and consequent hypertrophy of the right ventricle $(2,3)$. Surgical interventions during infancy mean that $85-90 \%$ of TOF patients now survive until at least 30 years of age $(1,4)$. However, this is not without consequence; event-free survival is just $25 \%$ after 40 years of age (5) since resultant scar tissue from surgery and pulmonary regurgitation cause significant morbidity in adulthood $(6,7)$.

The cause of TOF is elusive and no single candidate gene can be held accountable for the disease phenotype. However, the genetic status of syndromic TOF sufferers has 
provided valuable insights into causative genes in some patients. Approximately $20 \%$ of cases are associated with a recognised syndrome or chromosomal anomaly (2). Most significantly, approximately $15 \%$ of TOF patients have $22 q 11.2$ deletion syndrome, wherein the major causal gene is TBX1 $(8,9)$. In approximately $80 \%$ of TOF cases which are nonsyndromic there is generally not an identifiable cause, largely due to their non-Mendelian pattern of inheritance (10-13). Accordingly, a polygenic genetic architecture has been hypothesised and genome-wide approaches have been undertaken to provide insights into the complex genetic alterations responsible for TOF and other CHDs (11,13-18).

Whole exome sequencing (WES) has been used successfully to identify new CHD candidate genes $(14,17,19,20)$. Many lines of evidence indicate a degree of phenotypic specificity of variants in particular genes. For example, the spectrum of phenotypes caused by $22 q 11.2$ deletion or mutations in $T B X 1$ typically involves the outflow tract and great vessels, while Down's syndrome or mutations in NKX2.5 typically cause septal defects. To date, no WES study of CHD has included substantial numbers of any homogeneous phenotype, which should a priori have the highest power to identify causal variants.

Here, we present findings from WES of the largest cohort of non-syndromic TOF patients reported to date. First, we carried out a systematic review of the literature and identified 77 genes previously associated with either syndromic or non-syndromic TOF. We subsequently performed WES in 829 TOF probands and identified rare deleterious variants in the candidate genes. We sought evidence of pathological relevance for a subset of variants in the most significantly over-represented gene, based on the variants' de novo occurrence and functional consequences in cellular models.

\section{Methods Summary}

829 TOF probands were subjected to WES and rare (minor allele frequency [MAF] $\leq$ 0.001 in the Exome Aggregation Consortium [ExAC] database), deleterious (combined annotation-dependent depletion [CADD] score of $\geq 20$ ) variants in 77 TOF candidate genes 
were assessed. Any variants observed in 1252 reference exome samples, that were analysed using the same approach as our case data, were eliminated. Clustering analysis was used to identify genes where significantly more variants were observed than expected. De novo variants were identified by Sanger sequencing of proband parent samples. Immunoblotting and luciferase assays were used to assess the expression and signalling activity of selected variants. Detailed methods can be found in the Supplementary Data.

\section{Results}

\section{The NOTCH1 locus most frequently harbours rare, deleterious variants in non- syndromic TOF patients}

We assessed the incidence of rare, deleterious variants in 77 TOF candidate genes (Supplementary Table 1), for 829 non-syndromic TOF cases. Any variants observed in 1252 reference exomes were removed from consideration as a potential TOF susceptibility variant (Supplementary Table 2). Of the 77 genes considered, NOTCH1 was the locus most frequently found to harbour a rare (EXAC MAF $\leq 0.001)$, deleterious (CADD $\geq 20)$ variant among TOF patients (table 1), with 49 probands exhibiting 46 NOTCH1 variants, accounting for $6 \%$ of our TOF patient cohort $(95 \% \mathrm{Cl}: 4.5 \%-7.8 \%)$. The second most frequent locus was DOCK6, in which 30 probands harboured 26 rare, deleterious variants (table 1 ). The combined number of samples with $N O T C H 1$ or DOCK6 variants was 76 , highlighting the minimal overlap between probands with variants in these two genes (table 1). The statistical significance of these findings was assessed for each gene using clustering analysis which corrected for gene size; this confirmed a significant excess of rare, deleterious variants in six genes (figure 1); NOTCH1 ( $\mathrm{P}=1.89 \mathrm{E}-15)$, DOCK6 ( $\mathrm{P}=2.93 \mathrm{E}-7)$, MYOM2 ( $\mathrm{P}=7.35 \mathrm{E}-05)$, TTC37 $(\mathrm{P}=0.016)$, MESP1 $(\mathrm{P}=0.024)$ and TBX1 $(\mathrm{P}=0.039) .126$ TOF cases had a rare, deleterious variant in one or more of these genes, accounting for over $15 \%$ of our patient cohort. Clustering of variants identified in the remaining 71 candidate genes did not reach a corrected, $5 \%$ level of significance (Supplementary Table 3). When relaxing our stringent filters by removal of the CADD filter (Supplementary Table 4) and by increasing the MAF to 
$\leq 0.01$ (Supplementary Table 5), NOTCH1 continues to be the highest risk locus for nonsyndromic TOF, with $8 \%$ of our cohort carrying NOTCH1 variants.

\section{NOTCH1 variants cluster within the EGF-like repeats}

We mapped the distribution of the 46 NOTCH1 variants (Supplementary Table 6) to the various domains of the NOTCH1 protein (figure 2). Six of the variants identified were loss-of-function (LOF; figure 2), including three premature stop codons (p.R448* ${ }^{\star}$, p.W1638* and p.Q1733*) and three single base pair deletions resulting in frameshifts and eventual premature truncation (p.G115fs*6, p.N147fs* 128 and p.C1322fs*121). The three frameshift mutations were mapped to the EGF-like repeats in addition to one truncating mutant, p.R448*, whereas the remaining two truncating variants were located in the heterodimerisation domain (HD). Thus, all six LOF variants in NOTCH1 were located in the extracellular domain of the protein. Of the remaining 40 missense variants, 21 were located in amino acid residues that are conserved with Drosophila melanogaster Notch. 22 of the missense variants were novel whereas the remaining 18 were reported in the ExAC database with very low frequency $(\mathrm{MAF}<0.001)$. Rare, deleterious variants were located throughout the NOTCH1 protein (figure 2), mapping to both the extracellular domain and the intracellular domain. However, significantly more variants were located in the EGF-like repeats ( $p=0.018$; Supplementary Table 7 ), after adjustment for the proportion of the protein made up by EGF-like repeats. This region represents $56 \%$ of the total protein yet harbours $74 \%$ of NOTCH1 variants. With appropriate caveat for this having been a post hoc analysis informed by our knowledge of the variant distribution, these data suggest that rare and deleterious variants in TOF are significantly enriched in the EGF-like repeats of NOTCH1. Of the intracellular domain mutants, two missense variants in the Ankyrin domain region, p.R2004L and p.A2036T, are particularly notable. R2004 is a surface exposed residue in Ankyrin domain 4 which is located in an interface region with the CSL transcription factor complex (21) and also located at an interface that binds the positive Notch regulator, Deltex 
(22). A2036 is located in Ankyrin domain 5 and lies immediately adjacent to the location of a Drosophila developmental mutant $N^{\text {Su(42C) }}$ which is reported to reduce Notch activity (23).

\section{De novo variants identified in NOTCH1}

We investigated the occurrence rate of de novo mutations in probands with NOTCH1 variants. Of the 49 probands in our TOF patient cohort that harboured rare, deleterious variants in NOTCH1, samples from both parents were available for thirteen probands and analysed for variant inheritance. Following Sanger sequencing, five of the thirteen NOTCH1 variants tested were identified as de novo; two of these were truncating variants, whereas the remaining three de novo variants were missense (table 2). All de novo variants identified were absent in the ExAC database and not previously reported in the literature. The remaining variants sequenced were inherited from parents and five of these were of maternal origin. Of the eight inherited variants, six were listed in ExAC with very low frequency (table 2); the remaining two variants have not been previously reported. These findings are in keeping with the results of previous WES experiments in CHD, where rare transmitted variants with strong bioinformatic support for functional impact, which are of presumed incomplete penetrance, have been uniformly encountered $(14,17,20)$.

\section{NOTCH1 variants can affect NOTCH1 processing and signalling function}

The NOTCH1 gene encodes an evolutionarily conserved transmembrane receptor that mediates cell-cell communication to govern cell fate decisions during development (24). S1 cleavage is an important step in the maturation of the NOTCH1 receptor. During this process, the $300 \mathrm{kDa}$ translation product of NOTCH1 undergoes cleavage in the Golgi by furin-like convertase to generate two polypeptides of 180 and $120 \mathrm{kDa}$ (25). To determine whether NOTCH1 variants affect S1 cleavage, we assessed the expression of three $\mathrm{NOTCH} 1$ variants in comparison to WT NOTCH1 by immunoblotting. The variants assessed were p.G200R, p.C607Y and p.N1875S (figure 2); p.G200R is located in a conserved residue located within a $\beta$-hairpin turn within EGF5, and p.C607Y, located in EGF16, removes a conserved disulphide bond that normally would be expected to stabilise the EGF- 
domain conformation. p.N1875S is located in a residue that lies in a linker region between the RAM and Ankyrin regions of the Notch intracellular domain. As expected, we observed two bands at $300 \mathrm{kDa}(\mathrm{P} 300)$ and $120 \mathrm{kDa}$ (P120), representing full length and cleaved NOTCH1 protein (25); the remaining $180 \mathrm{kDa}$ product was not detectable due to the positioning of our FLAG-tag at the C-terminus (figure 3a). For WT NOTCH1, p.G200R and p.N1875S variants, we observe similar levels of both P300 and P120 (figure 3a). However, the p.C607Y variant exhibited perturbed cleavage by furin-like convertase (25). Indeed, quantification confirmed that $5 \% \pm 0.37 \%$ of $\mathrm{NOTCH} 1$ p.C607Y underwent cleavage in comparison to $57 \% \pm 3.96 \%$ of WT NOTCH1 ( $P=0.0002$; figure $3 b)$. Hence, the p.C607Y variant affects the processing of $\mathrm{NOTCH} 1$, whereas the receptor is processed normally in the presence of p.G200R and p.N1875S variants.

Heterodimeric NOTCH1 is membrane tethered and undergoes further cleavage by $\mathrm{Y}^{-}$ secretase which releases the NOTCH intracellular domain (NICD). NICD subsequently translocates to the nucleus where it interacts with transcription factor RBPJ to activate NOTCH target genes (24). To determine whether p.G200R, p.C607Y and p.N1875S variants affect $\mathrm{NOTCH} 1$ canonical signalling function, we assessed $\mathrm{NOTCH}$ signalling through the canonical, RBPJ transcription factor-dependent pathway following stimulation with immobilised Jagged1 ligand. The variants were overexpressed in HeLa cells and NOTCH1 signalling was assessed by RBPJ luciferase activity. All three variants demonstrated reduced NOTCH signalling via RBPJ (figure 3c). The p.C607Y variant, that exhibited perturbed cleavage, significantly reduced $\mathrm{NOTCH}$ signalling by $47 \% \pm 0.12 \%(P=0.008)$ compared to WT NOTCH1. Similarly, de novo variant p.N1875S reduced NOTCH signalling by $38 \% \pm 0.13 \%(P=0.02)$. The p.G200R variant reduced NOTCH signalling by $15 \% \pm 0.15 \%$, although this finding was not significant $(P=0.33)$ (figure 3c). No significant differences were observed between WT NOTCH1, p.G200R, p.C607Y and p.N1875S variants in the absence of JAG1 ligand. In each transfection experiment, mRNA expression of WT NOTCH1 and the three $\mathrm{NOTCH} 1$ variants was equal (data not shown), thus the differences in $\mathrm{NOTCH} 1$ signalling observed were not due to reduced mRNA expression of the variants. Hence, all 
three variants identified in patients that were subjected to functional testing were shown to affect canonical NOTCH1 signalling.

\section{Discussion}

TOF is the most common, severe cyanotic CHD; however, variants that could account for the high degree of genetic susceptibility inferred from familial recurrence risk studies (26) are as yet unidentified. Indeed, no single gene locus, with the exception of the $22 q 11$ deletion, has been found to account for any significant proportion of TOF cases. Through WES of a large cohort of sporadic, non-syndromic TOF, we show that NOTCH1 is an important susceptibility gene; $6 \%$ of patients carry heterozygous variants in NOTCH1 which, based on ExAC allele frequency, bioinformatic in silico prediction, and functional characterisation, we judged to be likely susceptibility alleles. Of the variants identified, $57 \%$ were novel, and the remainder have previously been reported in ExAC, but with very low frequency. Six of the variants were LOF, including truncating and frame shift mutations, whereas the remaining forty variants were missense and anticipated to be pathogenic. Five out of thirteen variants tested were de novo, adding to the evidence for pathogenicity; however the remaining variants were transmitted from unaffected parents indicating incomplete penetrance. As an additional safeguard against false positive results due to systematic methodological differences between our cohort and the studies which contributed to the ExAC database, we studied a set of over 1000 reference exomes in patients free from CHD, generated and analysed in the same fashion as the case exomes, removing any variant that appeared even once in the reference exome set from consideration as a potential TOF susceptibility variant.

Previous sequencing studies of CHD have identified an association of $\mathrm{NOTCH1}$ variants in left-sided cardiac malformations including bicuspid aortic valve, aortic valve stenosis, coarctation of the aorta and hypoplastic left heart syndrome (27-30). Like TOF, the causative $\mathrm{NOTCH} 1$ variants described for these conditions are mostly missense with a small number of LOF variants located throughout the NOTCH1 protein. In contrast, few studies, 
which included only a small number of patients, have implicated NOTCH1 variants in nonsyndromic TOF $(27,31)$. However, there are no clear distinctions between the type and location of NOTCH1 variants identified in TOF compared to those reported in other isolated cardiovascular abnormalities. We therefore propose that genetic background and/or environmental influences may specify phenotypic expressivity.

The association of NOTCH1 with cardiac defects beyond left-sided lesions is consistent with the reported roles of NOTCH1 during heart development. Active NOTCH1 is observed in trabecular endocardium and both global and endothelial-specific knockout of Notch1 in mice results in abnormal ventricular trabeculae and abnormal cardiomyocyte patterning (32). Relevant to TOF, Notch1 plays a role in the organisation of the outflow tract, which requires the specification of cells from both the neural crest and secondary heart field (33). Furthermore, Notch1 is important for endocardial epithelial-to-mesenchymal transition, a process that is essential for cardiac valve formation $(29,34)$. It should however be noted that all NOTCH1 variants we report are heterozygous. There are numerous reports of global and tissue specific NOTCH1 heterozygous mice that appear phenotypically normal, with no obvious cardiovascular pathologies $(35,36)$. However, in a more recent study that assessed ascending aortic aneurysm, $\mathrm{NOTCH}^{+/}$in a predominantly $129 \mathrm{~S} 6$ background developed aortic root dilation; and this was in contrast to $\mathrm{NOTCH}^{+/}$in a mixed background (37). These findings highlight the importance of genetic background in disease expressivity and are consistent with the incomplete penetrance observed.

Mutations in key cardiac transcription factors such as NKX2.5 (38), GATA4 (39), HAND2 (12) and GATA6 (40) have been identified in TOF cases, typically by targeted candidate gene sequencing; however these genes appear to account for just $1.7 \%$ of cases in our cohort. A Genome Wide Association Study (GWAS) of TOF cases versus controls identified risk alleles for single nucleotide polymorphisms (SNPs) in chromosomal regions 12q24 and 13q32, including the PTPN11 and GPC5 loci, respectively $(13,16)$. Additionally, duplications in 1q21.1 are strongly enriched in TOF patients $(11,31)$. Our findings, which in 
addition to NOTCH1 showed significant enrichment in five other genes (including TBX1, a well-established TOF risk gene which is principally responsible for the cardiac manifestations of 22q11 deletion) concur with previous studies regarding the marked locus heterogeneity of the condition. A possible role for NOTCH1 in non-syndromic TOF has previously been suggested by CNV analysis. A study of 34 infants with non-syndromic TOF revealed two patients with $\mathrm{CNVs}$ encompassing the NOTCH1 gene (41). Additionally, a microdeletion including the NOTCH1 locus in a patient with TOF was identified in a study of CNVs in 114 TOF patients (31). A recent study that focused primarily on families with leftsided CHD, identified family members with TOF harbouring pathogenic mutations in NOTCH1 (27). Further indirect evidence came from a study that analysed the gene expression patterns in TOF patient right ventricles and found many genes from the NOTCH and WNT signalling pathways were significantly reduced. Interestingly, down-regulation of NOTCH signalling components was also observed in TOF patients with a 22q11.2 deletion (42), highlighting a common transcriptional signature between both syndromic and nonsyndromic TOF, initiated by different genetic events. However, the present study involves, by a substantial margin, the largest TOF cohort studied by WES to date, providing the most accurate estimate thus far of the contribution of $\mathrm{NOTCH} 1$ variants to TOF risk.

De novo mutations are a significant cause of early-onset genetic disorders, including CHD. Of the NOTCH1 variants identified in this study, where parents were available, five of thirteen variants were found to be de novo, all of which were novel variants not previously reported on ExAC. Furthermore, de novo variant p.N1875S was shown to have significantly reduced Jagged1-induced NOTCH signalling relative to WT NOTCH1, providing further support as to the pathogenicity of de novo variants. However, other variants were inherited from an unaffected parent, confirming the role of incompletely penetrant variants observed for other CHD genes and phenotypes $(17,20)$. The incomplete penetrance is in keeping with the complex genetic aetiology of non-syndromic TOF, in which families segregating the 
condition in a Mendelian fashion are rarely encountered and genetic background in addition to in utero environmental factors can be inferred to play significant roles.

Recently, Blue et al (2014) identified the NOTCH1 missense variant p.G200R, which was independently found in the present study, to segregate with disease in two cousins with right-sided CHD. Cardiovascular malformations included persistent truncus arteriosus, VSD, pulmonary atresia, and major aorto-pulmonary collateral arteries. Furthermore, a case of TOF was also reported in the preceding generation, although sequencing analysis was not carried out on this relative. Our functional assessment of this variant showed reduced Jagged1-induced canonical NOTCH signalling. $\mathrm{NOTCH} 1$ is extremely LOF intolerant, with a probability of being LOF intolerant (pLI) of 1.0 on ExAC. Thus, even mild changes in its signalling ability could potentially have negative consequences during development. Hence, co-segregation of p.G200R with disease, in addition to reduced signalling capacity in in vitro experimentation provide evidence as to possible pathogenicity of this variant, albeit with incomplete penetrance (43). The p.C607Y missense variant perturbed NOTCH1 receptor cleavage by the calcium-dependent enzyme, furin-like convertase. The cleavage site is located at amino acids 1651 - 1654, some distance away from the variant. A similar observation has been reported by McBride et al (2008) where NOTCH1 variant p.A683T, identified in two patients with left ventricular outflow tract malformations, also perturbed S1 cleavage by similar levels. In both cases, this led to a $50 \%$ reduction in RBPJ luciferase activity (44). The mechanism by which such variants alter $S 1$ cleavage requires further research.

Autosomal dominant germ-line mutations in the $\mathrm{NOTCH} 1$ gene are one of the causes of Adams-Oliver syndrome (AOS) which is chiefly characterised by aplasia cutis congenita and terminal transverse limb defects. In addition, around half of patients exhibit congenital cardiac anomalies, including atrial septal defect (ASD), VSD, aortic valve stenosis, pulmonary valve stenosis and TOF $(51,52)$. AOS is an extremely rare syndrome, with a prevalence of approximately 1 in 225,000 (52). No patient in our cohort had diagnostic 
features of AOS. Like TOF, the causative NOTCH1 variants described for AOS are both missense and LOF variants that are not confined to one specific protein domain; however, the majority of reported variants are similarly located in the EGF-like repeats $(51,52)$. There are no clear distinctions between the NOTCH1 variants we have identified in TOF versus those that cause AOS, though no previously described AOS variant was present in our cases. The extra-cardiac features of AOS have been suggested to be due to early embryonic vascular abnormalities (53); this raises the possibility that AOS, TOF and other cardiac anomalies that occur due to mutations in NOTCH1 may be a spectrum of disorders. Other examples of syndromic genes that can cause isolated CHD, including TOF, are PTPN11 (Noonan's syndrome), (13,54), TBX5 (Holt-Oram syndrome) (55) and JAG1 (Alagille syndrome) (56). Determining the role of genetic background, environmental context and the specific NOTCH1 variants in determining the severity of the cardiac phenotype and the occurrence of extra-cardiac malformations requires further research.

The second gene identified in the current study, DOCK6, has also been identified as a causative gene in AOS, responsible for an autosomal-recessive form, often associated with impaired vascular function $(57,58)$. The DOCK6 gene encodes a highly conserved member of the Dedicator of Cytokinesis family and functions as an atypical nucleotide exchange factor. Specifically, DOCK6 plays a role in the remodelling of the actin cytoskeleton by activating two members of the Rho GTPase family, CDC42 and RAC1 (59). Studies thus far have demonstrated a role for DOCK6 in axonal extension and branching during neuronal development $(59,60)$. Presently, there is no simple functional read out for DOCK6, precluding detailed characterisation of the variants we discovered in cellular systems. However, investigations into a possible role for DOCK6 in cardiovascular development would be of interest.

In addition to NOTCH1 and DOCK6, significant clustering of rare, deleterious variants was also observed in an additional four genes, MYOM2, TTC37, MESP1 and TBX1, 
accounting for approximately $4 \%$ of TOF cases in our cohort. These findings emphasise the genetic heterogeneity that may ultimately lead to a TOF phenotype. The MYOM2 gene encodes Myomesin-2, a well characterised sarcomeric protein that is a major structural component of the myofibrillar M band. Mutations in MYOM2 have been identified in hypertrophic cardiomyopathy (61) and more recently, Grunert et al (2014) reported four nonsyndromic TOF cases with deleterious variants in MYOM2. TTC37 encodes Tetratricopeptide Repeat Domain 37 responsible for Trichohepatoenteric syndrome 1 (THES). THES is an autosomal-recessive disorder characterised by life threatening diarrhoea during infancy accompanied by immunodeficiency, liver disease, facial dysmorphia, hypopigmentation and cardiac defects. Cardiac defects are reported in approximately $25 \%$ of THES cases and include TOF, VSD and ASD $(62,63)$. The molecular function of TTC37 is poorly characterised and its role during heart development unknown. MESP1 encodes for Mesoderm posterior basic helix-loop-helix transcription factor 1, which plays an essential role during heart development. Mesp1 is expressed in cardiac progenitors and participates in the timely specification of the cardiac lineage in mouse cardiac development (64-66). Investigations in mice suggest Mesp1 may act upstream of critical cardiac transcription factors including Hand2, Gata4, Nkx2.5 and Tbx20 (64,65). In a previous study, six rare, non-synonymous MESP1 variants were identified in 647 patients with congenital conotruncal and related heart defects, including TOF (67). Finally, TBX1 encodes T-box transcription factor 1 which has important roles during development including the migration of cardiac neural crest cells and cellular proliferation in the second heart field (68). TBX1 is also responsible for the cardiac abnormalities associated with the $22 \mathrm{q} .11 .2$ deletion syndrome (69), which is the major contributor to the incidence of TOF $(8,9)$. In agreement with Griffin et al (2010), the present study confirms that rare, deleterious TBX1 variants contribute to a small proportion of non-syndromic TOF cases (70).

In summary, among the genes that have been implicated in TOF thus far, our large study indicates that of the 77 TOF candidate genes tested, no gene accounts for more than 
$8 \%$ (upper 95\% binomial confidence interval) of non-syndromic TOF. Among these genes NOTCH1 is the most commonly involved. The two most commonly involved genes (NOTCH1 and DOCK6) are also both involved in the predisposition to AOS, suggesting further investigation of common pathways between these conditions may be fruitful. Some mutations in $\mathrm{NOTCH} 1$ that are associated with TOF were de novo, but others were present in apparently asymptomatic individuals, indicating incomplete penetrance. Such incomplete penetrance has been prominently observed, for example, in Mendelian aortopathies, emphasising the importance of genetic background in structural cardiac and vascular diseases. Detailed phenotypic studies of mutation carriers who do not have overt CHD using advanced imaging may be of interest to delineate quantitative phenotypes potentially relevant to $\mathrm{CHD}$.

\section{Acknowledgements}

This work was supported by the British Heart Foundation. BK and SB hold BHF Personal Chairs. SB was supported by the BHF funded GOCHD study project grant. BM, CRB and AP were supported by the Netherlands Heart Foundation CVON project CONCOR-genes (CVON 2014-18). The work in Nottingham/Leicester was funded by BHF Programme Grant RG/13/10/30376. This study makes use of the ICR1000 UK exome series data generated by Professor Nazneen Rahman's Team at The Institute of Cancer Research, London (71).

\section{$\underline{\text { References }}$}

1. Ferencz C, Rubin JD, McCarter RJ, Brenner JI, Neill CA, Perry LW, Hepner SI, Downing JW. Congenital heart disease: prevalence at livebirth. The Baltimore-Washington Infant Study. Am J Epidemiol. 1985;121:31-36.

2. Bailliard F, Anderson RH. Tetralogy of Fallot. Orphanet J Rare Dis. 2009;4:2.

3. Shinebourne EA, Babu-Narayan SV, Carvalho JS. Tetralogy of Fallot: from fetus to adult. Heart. 2006;92:1353. 
4. Starr JP. Tetralogy of Fallot: Yesterday and Today. World Journal of Surgery. 2009;34:658.

5. Cuypers JA, Menting ME, Konings EE, Opić P, Utens EM, Helbing WA, Witsenburg M, van den Bosch AE, Ouhlous M, van Domburg RT, Rizopoulos D, Meijboom FJ, Boersma E, Bogers AJ, Roos-Hesselink JW. Unnatural History of Tetralogy of Fallot: Prospective FollowUp of 40 Years After Surgical Correction. Circulation. 2014;130:1944.

6. Folino AF, Daliento L. Arrhythmias after tetralogy of Fallot repair. Indian pacing and electrophysiology journal. 2005; 5(4): 312-324

7. Fuller S. Tetralogy of Fallot and Pulmonary Valve Replacement: Timing and Techniques in the Asymptomatic Patient. Seminars in Thoracic and Cardiovascular Surgery: Pediatric Cardiac Surgery Annual. 2014;17:30.

8. Mercer-Rosa L, Rychik J, Zhao H, Zhang X, Yang W, Shults J, Goldmuntz E. 22q11.2 Deletion Status and Disease Burden in Children and Adolescents With Tetralogy of Fallot. CLINICAL PERSPECTIVE. Circulation: Cardiovascular Genetics. 2015;8:74.

9. Lindsay EA, Vitelli F, Su H, Morishima M, Huynh T, Pramparo T, Jurecic V, Ogunrinu G, Sutherland HF, Scambler PJ, Bradley A, Baldini A. Tbx1 haploinsufficieny in the DiGeorge syndrome region causes aortic arch defects in mice. Nature. 2001;410:97-101.

10. Doza JP, Topf A, Bentham J, Bhattacharya S, Cosgrove C, Brook JD, Granados-Riveron J, Bu'Lock FA, O'Sullivan J, Stuart AG, Parsons J, Relton C, Goodship J, Henderson DJ, Keavney B. Low-frequency intermediate penetrance variants in the ROCK1 gene predispose to Tetralogy of Fallot. BMC Genet. 2013;14:57.

11. Soemedi R, Topf A, Darlay R, Rahman T, Glen E, Hall D, Huang N, Bentham J, Bhattacharya S, Cosgrove C, Granados-Riveron J, Setchfield K, Bu'Lock F, Thornborough C, Devriendt K, Breckpot J, Hofbeck M, Lathrop M, Rauch A, Hurles M, Santibanez-Koref M. Cordell HJ, Goodship JA, Keavney BD. Phenotype-specific effect of chromosome 1q21.1 rearrangements and GJA5 duplications in 2436 congenital heart disease patients and 6760 controls. Human Molecular Genetics. 2011;21:1513. 
12. Griffin HR, Glen E, Soemedi R, Brown DL, Hall D, Rahman TJ, Eloranta JJ, Jüngst C, Stuart AG, O'Sullivan J, Keavney BD, Goodship JA. Functionally significant, rare transcription factor variants in tetralogy of Fallot. PLOS ONE. 2014;9:e95453.

13. Goodship JA, Hall D, Topf A, Mamasoula C, Griffin H, Rahman TJ, Glen E, Tan H, Palomino Doza J, Relton CL, Bentham J, Bhattacharya S, Cosgrove C, Brook D, GranadosRiveron J, Bu'Lock FA, O'Sullivan J, Stuart AG, Parsons J, Cordell HJ, Keavney B. A Common Variant in the PTPN11 Gene Contributes to the Risk of Tetralogy of Fallot. Circulation: Cardiovascular Genetics. 2012;5:287.

14. Zaidi S, Choi M, Wakimoto H, Ma L, Jiang J, Romano-Adesman A, Cheung YH, Deanfield J, DePalma S, Glessner J, Hakonarson H, Kaski J, Kim R, Lee T, Leipzig J, Lopez A, Parfenov M, Pe'er I, Porter G, Sachidanandam R, Subramanian S, Wang W, Warburton D, Zhao H, Brueckner M, Goldmuntz E. De novo mutations in histone-modifying genes in congenital heart disease. Nature. 2013;498:220.

15. Cordell HJ, Bentham J, Topf A, Zelenika D, Heath S, Mamasoula C, Cosgrove C, Blue G, Granados-Riveron J, Setchfield K, Thornborough C, Breckpot J, Soemedi R, Martin R, Rahman TJ, Hall D, van Engelen K, Moorman AFM, Zwinderman AH, Barnett P, Koopmann TT, Adriaens ME, Varro A, George AL, Remedios dos C, Bishopric NH, Bezzina CR, O'Sullivan J, Gewillig M, Bu'Lock FA, Winlaw D, Bhattacharya S, Devriendt K, Brook JD, Mulder BJ, Mital S, Postma AV, Lathrop GM, Farrall M, Goodship JA, Keavney BD. Genome-wide association study of multiple congenital heart disease phenotypes identifies a susceptibility locus for atrial septal defect at chromosome 4p16. Nature Genetics. 2013;45:822.

16. Cordell HJ, Mamasoula C, Postma AV, Bentham J, Zelenika D, Heath S, Blue G, Cosgrove C, Riveron JG, Darlay R, Soemedi R, Wilson IJ, Ayers KL, Rahman TJ, Hall D, Mulder BJM, Zwinderman AH, van Engelen K, Brook JD, Setchfield K, Bu'Lock FA, Thornborough C, O'Sullivan J, Stuart AG, Parsons J, Bhattacharya S, Winlaw D, Mital S, Gewillig M, Breckpot J, Devriendt K, Moorman AF, Rauch A, Lathrop GM, Keavney BD, 
Goodship JA. Genome-wide association study identifies loci on 12q24 and 13q32 associated with tetralogy of Fallot. Human Molecular Genetics. 2013;22:1473-1481.

17. Homsy J, Zaidi S, Shen Y, Ware JS, Samocha KE, Karczewski KJ, DePalma SR, McKean D, Wakimoto H, Gorham J, Jin SC, Deanfield J, Giardini A, Porter GA Jr, Kim R, Bilguvar K, López-Giráldez F, Tikhonova I, Mane S, Romano-Adesman A, Qi H, Vardarajan B, Ma L, Daly M, Roberts AE, Russell MW, Mital S, Newburger JW, Gaynor JW, Breitbart RE, lossifov I, Ronemus M, Sanders SJ, Kaltman JR, Seidman JG, Brueckner M, Gelb BD, Goldmuntz E, Lifton RP, Seidman CE, Chung WK. De novo mutations in congenital heart disease with neurodevelopmental and other congenital anomalies. Science. 2015;350:1262. 18. Soemedi R, Bentham J, Darlay R, Zelenika D, Cosgrove C, Setchfield K, Thornborough C, Granados-Riveron J, Breckpot J, Hellens S, Zwolinkski S, Glen E, Mamasoula C, Hall D, Rauch A, Devriendt K, Gewillig M, Bhattacharya S, Lathrop M, Santibanez-Koref M, Cordell HJ, Goodship JA, Keavney BD. Contribution of Global Rare Copy-Number Variants to the Risk of Sporadic Congenital Heart Disease. The American Journal of Human Genetics. 2012;91:489.

19. Turki AI S, Manickaraj AK, Mercer CL, Gerety SS, Hitz M-P, Lindsay S, D'Alessandro LCA, Swaminathan GJ, Bentham J, Arndt A-K, Louw J, Low J, Breckpot J, Gewillig M, Thienpont B, Abdul-Khaliq H, Harnack C, Hoff K, Kramer H-H, Schubert S, Siebert R, Toka O, Cosgrove C, Watkins H, Lucassen AM, O'Kelly IM, Salmon AP, Bu'Lock FA, GranadosRiveron J, Setchfield K, Thornborough C, Brook JD, Mulder B, Klaassen S, Bhattacharya S, Devriendt K, FitzPatrick DR; UK10K Consortium, Wilson DI, Mital S, Hurles ME. Rare variants in NR2F2 cause congenital heart defects in humans. The American Journal of Human Genetics. 2014;94:574-585.

20. Sifrim A, Hitz M-P, Wilsdon A, Breckpot J, Turki Al SH, Thienpont B, McRae J, Fitzgerald TW, Singh T, Swaminathan GJ, Prigmore E, Rajan D, Abdul-Khaliq H, Banka S, Bauer UMM, Bentham J, Berger F, Bhattacharya S, Bu'Lock F, Canham N, Colgiu I-G, Cosgrove C, Cox H, Daehnert I, Daly A, Danesh J, Fryer A, Gewillig M, Hobson E, Hoff K, Homfray T; INTERVAL Study, Kahlert AK, Ketley A, Kramer HH, Lachlan K, Lampe AK, Louw JJ, 
Manickara AK, Manase D, McCarthy KP, Metcalfe K, Moore C, Newbury-Ecob R, Omer SO, Ouwehand WH, Park SM, Parker MJ, Pickardt T, Pollard MO, Robert L, Roberts DJ, Sambrook J, Setchfield K, Stiller B, Thornborough C, Toka O, Watkins H, Williams D, Wright M, Mital S, Daubeney PE, Keavney B, Goodship J; UK10K Consortium, Abu-Sulaiman RM, Klaassen S, Wright CF, Firth HV, Barrett JC, Devriendt K, FitzPatrick DR, Brook JD; Deciphering Developmental Disorders Study, Hurles ME. Distinct genetic architectures for syndromic and nonsyndromic congenital heart defects identified by exome sequencing.

Nature Genetics. 2016;48:1060-1065.

21. Choi SH, Wales TE, Nam Y, O'Donovan DJ, Sliz P, Engen JR, Blacklow SC. Conformational locking upon cooperative assembly of notch transcription complexes. Structure. 2012;20:340-349.

22. Shimizu H, Woodcock SA, Wilkin MB, Trubenová B, Monk NAM, Baron M. Compensatory flux changes within an endocytic trafficking network maintain thermal robustness of Notch signaling. Cell. 2014;157:1160-1174.

23. Diederich RJ, Matsuno K, Hing H, Artavanis-Tsakonas S. Cytosolic interaction between deltex and Notch ankyrin repeats implicates deltex in the Notch signaling pathway.

Development. 1994;120:473-481.

24. Andersen P, Uosaki H, Shenje LT, Kwon C. Non-canonical Notch signaling: emerging role and mechanism. Trends in Cell Biology. 2012;22:257.

25. Logeat F, Bessia C, Brou C, LeBail O. The Notch1 receptor is cleaved constitutively by a furin-like convertase. Proceedings of the National Academy of Sciences. 1998; 95(14):810812.

26. Burn J, Brennan P, Little J, Holloway S, Coffey R, Somerville J, Dennis NR, Allan L, Arnold R, Deanfield JE, Godman M, Houston A, Keeton B, Oakley C, Scott O, Silove E, Wilkinson J, Pembrey M, Hunter AS. Recurrence risks in offspring of adults with major heart defects: results from first cohort of British collaborative study. Lancet. 1998;351:311-316. 27. Kerstjens-Frederikse WS, van de Laar IM, Vos YJ, Verhagen JM, Berger RM, Lichtenbelt KD, Klein Wassink-Ruiter JS, van der Zwaag PA, du Marchie Sarvaas GJ, 
Bergman KA, Bilardo CM, Roos-Hesselink JW, Janssen JH, Frohn-Mulder IM, van Spaendonck-Zwarts KY, van Melle JP, Hofstra RM, Wessels MW. Cardiovascular malformations caused by NOTCH1 mutations do not keep left: data on 428 probands with left-sided CHD and their families. Genetics in Medicine. 2016;18:914.

28. Yang C, Xu Y, Yu M, Lee D, Alharti S, Hellen N, Shaik NA, Banaganapalli B, Mohamoud HSA, Elango R, Przyborski S, Tenin G, Williams S, Al-Radi OO, Atta J, Harding SE, Keavney B, Lako M, Armstrong L. Induced pluripotent stem cell modelling of HLHS underlines the contribution of dysfunctional NOTCH signalling to impaired cardiogenesis. Human Molecular Genetics. 2017; 15; 26(16):3031-3045

29. McKellar SH, Tester DJ, Yagubyan M, Majumdar R, Ackerman MJ, Sundt TM. Novel $\mathrm{NOTCH} 1$ mutations in patients with bicuspid aortic valve disease and thoracic aortic aneurysms. J Thorac Cardiovasc Surg. 2007;134:290-296.

30. Iascone M, Ciccone R, Galletti L, Marchetti D, Seddio F, Lincesso AR, Pezzoli L, Vetro A, Barachetti D, Boni L, Federici D, Soto AM, Comas JV, Ferrazzi P, Zuffardi O. Identification of de novo mutations and rare variants in hypoplastic left heart syndrome. Clinical Genetics. 2011;81:542.

31. Greenway SC, Pereira AC, Lin JC, DePalma SR, Israel SJ, Mesquita SM, Ergul E, Conta JH, Korn JM, McCarroll SA, Gorham JM, Gabriel S, Altshuler DM, de Lourdes QuintanillaDieck M, Artunduaga MA, Eavey RD, Plenge RM, Shadick NA, Weinblatt ME, De Jager PL, Hafler DA, Breitbart RE, Seidman JG, Seidman CE. De novo copy number variants identify new genes and loci in isolated sporadic tetralogy of Fallot. Nature Genetics. 2009;41:931. 32. Grego-Bessa J, Luna-Zurita L, del Monte G, Bolós V, Melgar P, Arandilla A, Garratt AN, Zang H, Mukouyama Y-S, Chen H, Shou W, Ballestar E, Esteller M, Rojas A, PérezPomares JM, la Pompa de JL. Notch Signaling Is Essential for Ventricular Chamber Development. Dev Cell. 2007;12:415.

33. High FA, Jain R, Stoller JZ, Antonucci NB, Lu MM, Loomes KM, Kaestner KH, Pear WS, Epstein JA. Murine Jagged1/Notch signaling in the second heart field orchestrates Fgf8 
expression and tissue-tissue interactions during outflow tract development. Journal of Clinical Investigation. 2009; 119(7):1986-96

34. Timmerman LA. Notch promotes epithelial-mesenchymal transition during cardiac development and oncogenic transformation. Genes Dev. 2004;18:99.

35. Conlon RA, Reaume AG, Rossant J. Notch1 is required for the coordinate segmentation of somites. Development. 1995;121:1533-1545.

36. Swiatek PJ, Lindsell CE, del Amo FF, Weinmaster G, Gridley T. Notch1 is essential for postimplantation development in mice. Genes Dev. 1994;8:707.

37. Koenig SN, LaHaye S, Feller JD, Rowland P, Hor KN, Trask AJ, Janssen PM, Radtke F, Lilly B, Garg V. Notch1 haploinsufficiency causes ascending aortic aneurysms in mice. JCI Insight. 2017;2(21)

38. Goldmuntz E, Geiger E, Benson DW. NKX2.5 mutations in patients with tetralogy of fallot. Circulation. 2001;104:2565-2568.

39. Nemer G, Fadlalah F, Usta J, Nemer M, Dbaibo G, Obeid M, Bitar F. A novel mutation in the GATA4 gene in patients with Tetralogy of Fallot. Hum Mutat. 2006;27:293-294.

40. Lin X, Huo Z, Liu X, Zhang Y, Li L, Zhao H, Yan B, Liu Y, Yang Y, Chen Y-H. A novel GATA6 mutation in patients with tetralogy of Fallot or atrial septal defect. J Hum Genet. 2010;55:662-667.

41. Bittel DC, Zhou X-G, Kibiryeva N, Fiedler S, O’Brien JE, Marshall J, Yu S, Liu H-Y. Ultra High-Resolution Gene Centric Genomic Structural Analysis of a Non-Syndromic Congenital Heart Defect, Tetralogy of Fallot. PLoS ONE. 2014;9:e87472.

42. Bittel DC, Butler MG, Kibiryeva N, Marshall JA, Chen J, Lofland GK. Gene expression in cardiac tissues from infants with idiopathic conotruncal defects. BMC Medical Genomics. $2011 ; 4.1$

43. Blue GM, Kirk EP, Giannoulatou E, Dunwoodie SL, White SM, Sholler GF, Harvey RP, Winlaw DS. Targeted Next-Generation Sequencing Identifies Pathogenic Variants in Familial Congenital Heart Disease. Journal of the American College of Cardiology. 2014;64:2498. 
44. McBride KL, Riley MF, Zender GA, Fitzgerald-Butt SM, Towbin JA, Belmont JW, Cole SE. NOTCH1 mutations in individuals with left ventricular outflow tract malformations reduce ligand-induced signaling. Human Molecular Genetics. 2008;17:2886.

45. Shao L, Moloney DJ, Haltiwanger R. Fringe modifies O-fucose on mouse Notch1 at epidermal growth factor-like repeats within the ligand-binding site and the Abruptex region. Journal of Biological Chemistry. 2002;278:7775-7782.

46. Rampal R, Arboleda-Velasquez JF, Nita-Lazar A, Kosik KS, Haltiwanger RS. Highly conserved O-fucose sites have distinct effects on Notch1 function. Journal of Biological Chemistry. 2005;280:32133-32140.

47. Rutten JW, Haan J, Terwindt GM, van Duinen SG, Boon EMJ, Oberstein SAJL. Interpretation of NOTCH3 mutations in the diagnosis of CADASIL. Expert Rev Mol Diagn. 2014;14:593-603.

48. Joutel A, Monet-Leprêtre M, Gosele C, Baron-Menguy C, Hammes A, Schmidt S, Lemaire-Carrette B, Domenga V, Schedl A, Lacombe P, Hubner N. Cerebrovascular dysfunction and microcirculation rarefaction precede white matter lesions in a mouse genetic model of cerebral ischemic small vessel disease. Journal of Clinical Investigation. 2010;120:433-445.

49. Opherk C, Duering M, Peters N, Karpinska A, Rosner S, Schneider E, Bader B, Giese A, Dichgans M. CADASIL mutations enhance spontaneous multimerization of NOTCH3. Human Molecular Genetics. 2009;18:2761-2767.

50. Karlstrom H, Beatus P, Dannaeus K, Chapman G, Lendahl U, Lundkvist J. A CADASILmutated Notch 3 receptor exhibits impaired intracellular trafficking and maturation but normal ligand-induced signaling. Proceedings of the National Academy of Sciences. 2002;99:17119. 51. Southgate L, Sukalo M, Karountzos ASV, Taylor EJ, Collinson CS, Ruddy D, Snape KM, Dallapiccola B, Tolmie JL, Joss S, Brancati F, Digilio MC, Graul-Neumann LM, Salviati L, Coerdt W, Jacquemin E, Wuyts W, Zenker M, Machado RD, Trembath RC. Haploinsufficiency of the NOTCH1 Receptor as a Cause of Adams-Oliver Syndrome With Variable Cardiac Anomalies. Circulation: Cardiovascular Genetics. 2015;8:572-581. 
52. Stittrich A-B, Lehman A, Bodian DL, Ashworth J, Zong Z, Li H, Lam P, Khromykh A, lyer RK, Vockley JG, Baveja R, Silva ES, Dixon J, Leon EL, Solomon BD, Glusman G, Niederhuber JE, Roach JC, Patel MS. Mutations in NOTCH1 cause Adams-Oliver syndrome. The American Journal of Human Genetics. 2014;95:275-284.

53. Swartz EN, Sanatani S, Schreiber RA. Vascular abnormalities in Adams-Oliver syndrome: Cause or effect? American Journal of Medical Genetics. 1999;82:49.

54. Weismann CG, Hager A, Kaemmerer H, Maslen CL, Morris CD, Schranz D, Kreuder J, Gelb BD. PTPN11 mutations play a minor role in isolated congenital heart disease. American Journal of Medical Genetics Part A. 2005;136A:146.

55. Jia Y, Louw JJ, Breckpot J, Callewaert B, Barrea C, Sznajer Y, Gewillig M, Souche E, Dehaspe L, Vermeesch JR, Lambrechts D, Devriendt K, Corveleyn A. The diagnostic value of next generation sequencing in familial nonsyndromic congenital heart defects. American Journal of Medical Genetics Part A. 2015;167A:1822-1829.

56. Bauer RC, Laney AO, Smith R, Gerfen J, Woyciechowski S, Garbarini J, Loomes KM, Krantz ID, Urban Z, Gelb BD, Goldmuntz E, Spinner NB. Jagged1 (JAG1) mutations in patients with tetralogy of fallot or pulmonic stenosis. Hum Mutat. 2010;31:594.

57. Shaheen R, Faqeih E, Sunker A, Morsy H, Al-Sheddi T, Shamseldin HE, Adly N, Hashem M, Alkuraya. FS. Recessive Mutations in DOCK6, Encoding the Guanidine Nucleotide Exchange Factor DOCK6, Lead to Abnormal Actin Cytoskeleton Organization and Adams-Oliver Syndrome. The American Journal of Human Genetics. 2011;89:328. 58. Lehman A, Stittrich A-B, Glusman G, Zong Z, Li H, Eydoux P, Senger C, Lyons C, Roach JC, Patel M. Diffuse angiopathy in Adams-Oliver syndrome associated with truncating DOCK6 mutations. American Journal of Medical Genetics Part A. 2014;164:2656. 59. Miyamoto Y, Yamauchi J, Sanbe A, Tanoue A. Dock6, a Dock-C subfamily guanine nucleotide exchanger, has the dual specificity for Rac1 and Cdc42 and regulates neurite outgrowth. Experimental Cell Research. 2007;313:791. 
60. Miyamoto Y, Torii T, Yamamori N, Ogata T, Tanoue A, Yamauchi J. Akt and PP2A Reciprocally Regulate the Guanine Nucleotide Exchange Factor Dock6 to Control Axon Growth of Sensory Neurons. Sci STKE. 2013;6:ra15.

61. Siegert R, Perrot A, Keller S, Behlke J, Michalewska-Włudarczyk A, Wycisk A, Tendera M, Morano I, Özcelik C. A myomesin mutation associated with hypertrophic cardiomyopathy deteriorates dimerisation properties. Biochemical and Biophysical Research Communications. 2011;405:473.

62. Fabre A, Martinez-Vinson C, Goulet O, Badens C. Syndromic diarrhea/Tricho-hepatoenteric syndrome. Orphanet J Rare Dis. 2013;8:5.

63. Hartley JL, Zachos NC, Dawood B, Donowitz M, Forman J, Pollitt RJ, Morgan NV, Tee L, Gissen P, Knisely AS, Watson S, Chitayat D, Booth IW, Protheroe S, Murphy S, de Vries E, Kelly DA, Maher ER. Mutations in TTC37 Cause Trichohepatoenteric Syndrome (Phenotypic Diarrhea of Infancy). Gastroenterology. 2010;138:2388.

64. Bondue A, Lapouge G, Paulissen C, Semeraro C, lacovino M, Kyba M, Blanpain C. Mesp1 Acts as a Master Regulator of Multipotent Cardiovascular Progenitor Specification. Cell Stem Cell. 2008;3:69.

65. Lindsley RC, Gill JG, Murphy TL, Langer EM, Cai M, Mashayekhi M, Wang W, Niwa N, Nerbonne JM, Kyba M, Murphy KM. Mesp1 Coordinately Regulates Cardiovascular Fate Restriction and Epithelial-Mesenchymal Transition in Differentiating ESCs. Cell Stem Cell. 2008;3:55.

66. David R, Brenner C, Stieber J, Schwarz F, Brunner S, Vollmer M, Mentele E, MüllerHöcker J, Kitajima S, Lickert H, Rupp R, Franz WM. MesP1 drives vertebrate cardiovascular differentiation through Dkk-1-mediated blockade of Wnt-signalling. Nat Cell Biol. 2008;10:338.

67. Werner P, Latney B, Deardorff MA, Goldmuntz E. MESP1 Mutations in Patients with Congenital Heart Defects. Hum Mutat. 2016;37:308.

68. Calmont A, Ivins S, Van Bueren KL, Papangeli I, Kyriakopoulou V, Andrews WD, Martin JF, Moon AM, Illingworth EA, Basson MA, Scambler PJ. Tbx1 controls cardiac neural crest 
cell migration during arch artery development by regulating Gbx2 expression in the pharyngeal ectoderm. Development. 2009;136:3173.

69. Merscher S, Funke B, Epstein JA, Heyer J, Puech A, Lu MM, Xavier RJ, Demay MB, Russell RG, Factor S, Tokooya K, Jore BS, Lopez M, Pandita RK, Lia M, Carrion D, Xu H, Schorle H, Kobler JB, Scambler P, Wynshaw-Boris A, Skoultchi Al, Morrow BE, Kucherlapati R. TBX1 is responsible for cardiovascular defects in velo-cardio-facial/DiGeorge syndrome. Cell. 2001;104:619-629.

70. Griffin HR, Glen E, Zweier C, Stuart AG, Parsons J, Peart I, Deanfield J, O'Sullivan J, Rauch A, Scambler P, Burn J, Cordell HJ, Keavney B, Goodship JA. Systematic survey of variants in TBX1 in non-syndromic tetralogy of Fallot identifies a novel 57 base pair deletion that reduces transcriptional activity but finds no evidence for association with common variants. Heart. 2010;96:1651-1655.

71. Ruark E, Münz M, Renwick A, Clarke M, Ramsay E, Hanks S, Mahamdallie S, Elliott A, Seal S, Strydom A, Gerton L, Rahman N. The ICR1000 UK exome series: a resource of gene variation in an outbred population. F1000Research. 2015;4:883. 


\section{$\underline{\text { Tables }}$}

Table 1: The top 10 genes ordered by levels of significance following the clustering analysis of rare, deleterious variants

\begin{tabular}{|c|c|c|c|c|}
\hline Gene & $\begin{array}{l}\text { Non-synonymous variants } \\
\text { MAF } \leq 0.001, \text { CADD } \geq 20\end{array}$ & $P$ value & $\begin{array}{l}\text { Number of } \\
\text { samples }\end{array}$ & $\begin{array}{c}\text { Cumulative } \\
\text { unique samples }\end{array}$ \\
\hline NOTCH1 & 46 & $1.89 \mathrm{E}-15$ & 49 & 49 \\
\hline DOCK6 & 26 & 2.93E-07 & 30 & 76 \\
\hline MYOM2 & 19 & 7.35E-05 & 19 & 92 \\
\hline TTC37 & 16 & 0.015679285 & 16 & 108 \\
\hline MESP1 & 9 & 0.024101962 & 13 & 119 \\
\hline TBX1 & 8 & 0.038684321 & 8 & 126 \\
\hline STRA6 & 9 & 0.098187209 & 10 & 135 \\
\hline CHD7 & 18 & 0.797011426 & 20 & 150 \\
\hline HOXA1 & 6 & 0.799453623 & 6 & 155 \\
\hline SALL4 & 7 & 0.948417765 & 7 & 161 \\
\hline
\end{tabular}

MAF, minor allele frequency; CADD, combined annotation-dependent depletion 
Table 2: Sequencing of parent samples to determine NOTCH1 variant inheritance

\begin{tabular}{|c|c|c|c|c|c|c|c|}
\hline $\begin{array}{c}\text { Amino acid } \\
\text { change }\end{array}$ & Ref & Alt & LOF & Impact & $\begin{array}{c}\text { In } \\
\text { ExAC }\end{array}$ & MAF & Inheritance status \\
\hline p.V53M & C & $\mathrm{T}$ & NO & Missense variant & YES & 3.69E-05 & FROM MOTHER \\
\hline p.G200V & C & $A$ & NO & Missense variant & NO & - & DE NOVO \\
\hline p.C292Y & C & $\mathrm{T}$ & $\mathrm{NO}$ & Missense variant & $\mathrm{NO}$ & - & FROM MOTHER \\
\hline p.P407L & $\mathrm{G}$ & A & NO & Missense variant & YES & 8.34E-06 & FROM MOTHER \\
\hline p.T432M & $\mathrm{G}$ & $A$ & NO & Missense variant & YES & 0.000157 & FROM FATHER \\
\hline p.R448* & $G$ & $A$ & YES & Stop gained & NO & - & DE NOVO \\
\hline p.T984M & $\mathrm{G}$ & $A$ & NO & Missense variant & YES & 8.26E-06 & FROM MOTHER \\
\hline p.Q1495K & $\mathrm{G}$ & $\mathrm{T}$ & NO & Missense variant & NO & - & FROM FATHER \\
\hline p.C1549Y & C & $\mathrm{T}$ & NO & Missense variant & NO & - & DE NOVO \\
\hline p.W1638* & C & $\mathrm{T}$ & YES & Stop gained & NO & - & DE NOVO \\
\hline p.N1875S & $\mathrm{T}$ & $\mathrm{C}$ & NO & Missense variant & NO & - & DE NOVO \\
\hline p.A2036T & C & $\mathrm{T}$ & NO & Missense variant & YES & 8.26E-06 & FROM FATHER \\
\hline p.R2327Q & $\mathrm{C}$ & $\mathrm{T}$ & NO & Missense variant & YES & 0.000224 & FROM MOTHER \\
\hline
\end{tabular}

Ref, reference allele; Alt, alternate allele; LOF, loss of function; MAF, minor allele frequency 


\section{Fiqures}

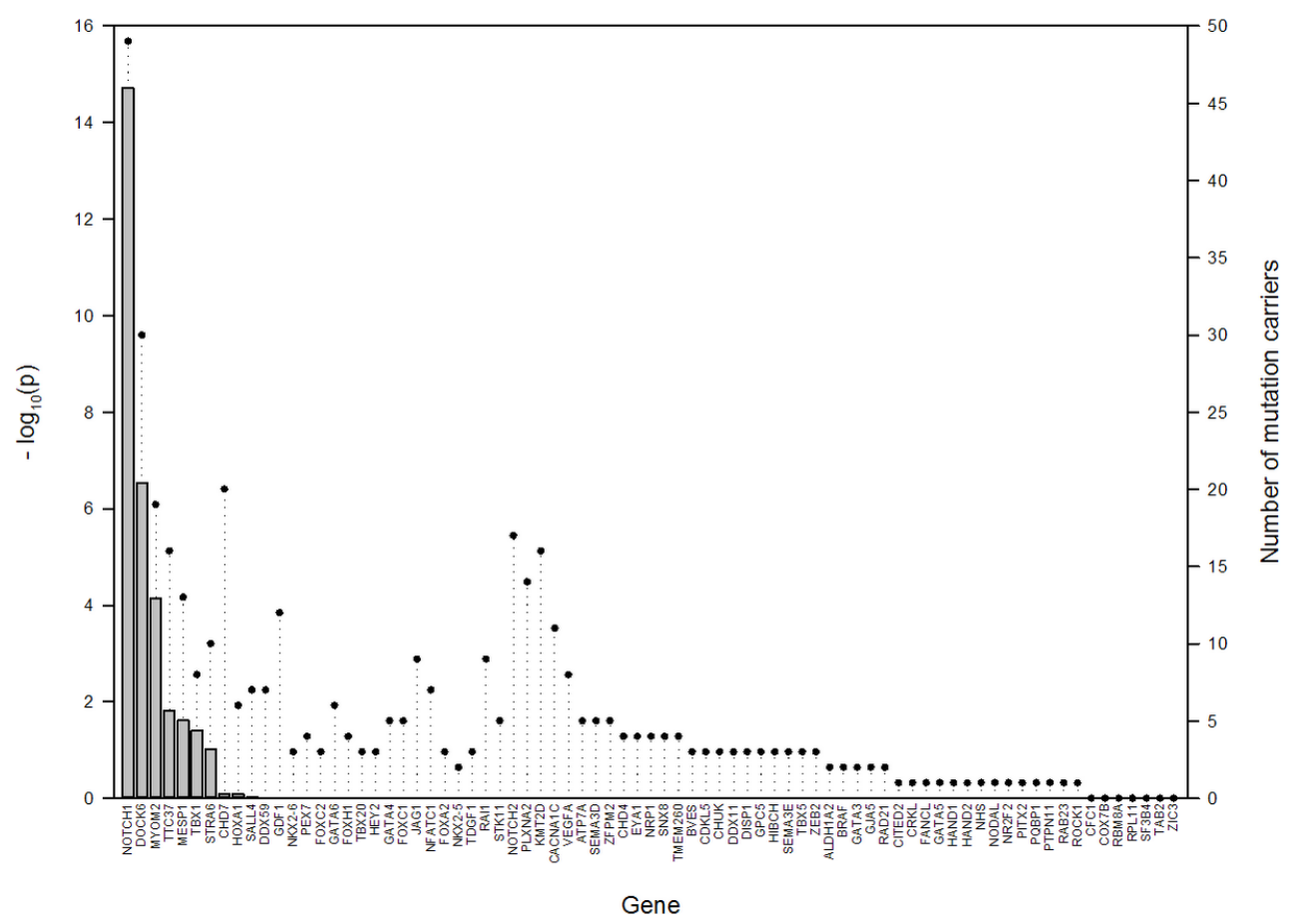

Figure 1: The number of patients carrying rare, deleterious variants in the 77 genes previously associated with syndromic or non-syndromic TOF. Bars indicate the respective significance levels of variant clustering for each gene, represented as -log P values. Circles represent the number of mutation carriers. 


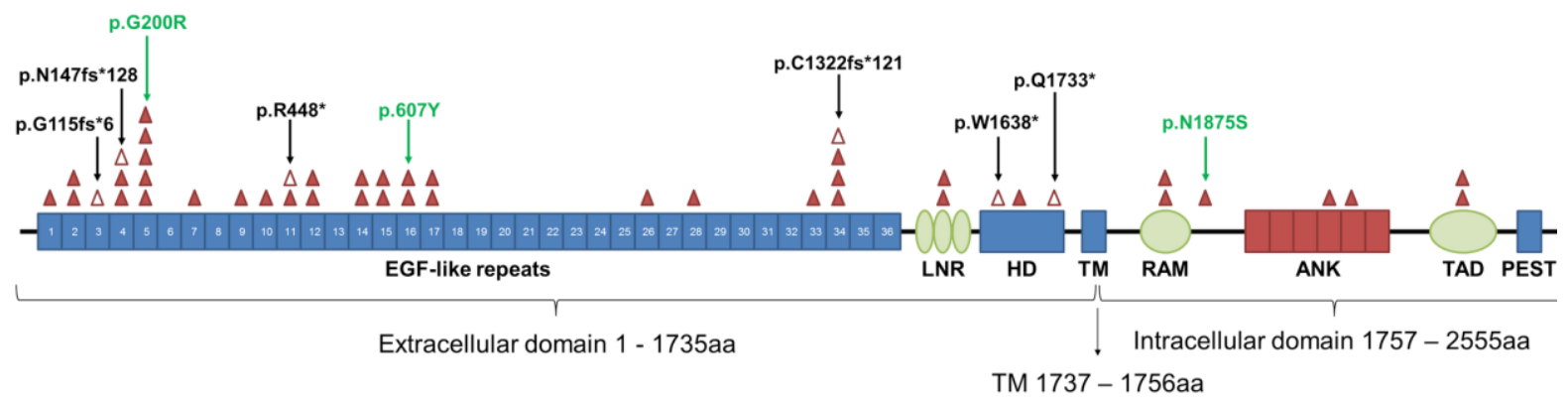

Figure 2: The NOTCH1 protein structure and location of rare, deleterious mutations in TOF patients. Variants were mapped to the known protein domains of NOTCH1. Missense variants are indicated by closed triangles and loss-of-function (truncating/frameshift) variants are indicated by open triangles and annotated in black. Missense variants p.G200R, p.C607Y and p.N1875S, which are of relevance to subsequent analyses, are indicated in green. ANK, ankyrin repeats; EGF, epidermal growth factor; HD, heterodimerisation domain; LBR, ligand binding region; LNR, Lin/Notch repeats; PEST, PEST domain; RAM, RBPJassociated molecule domain; TAD, transactivation domain; TM, transmembrane domain. 
a

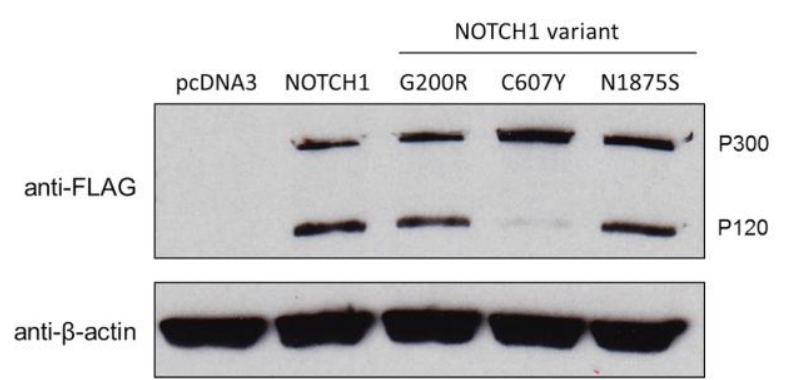

b

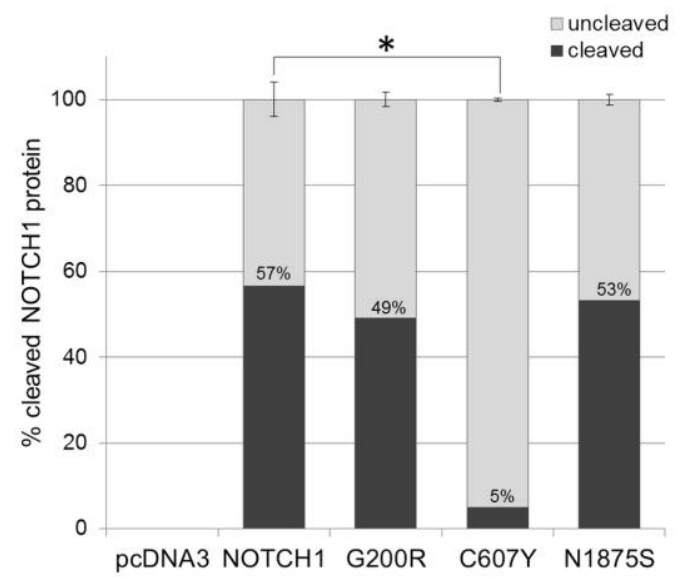

C

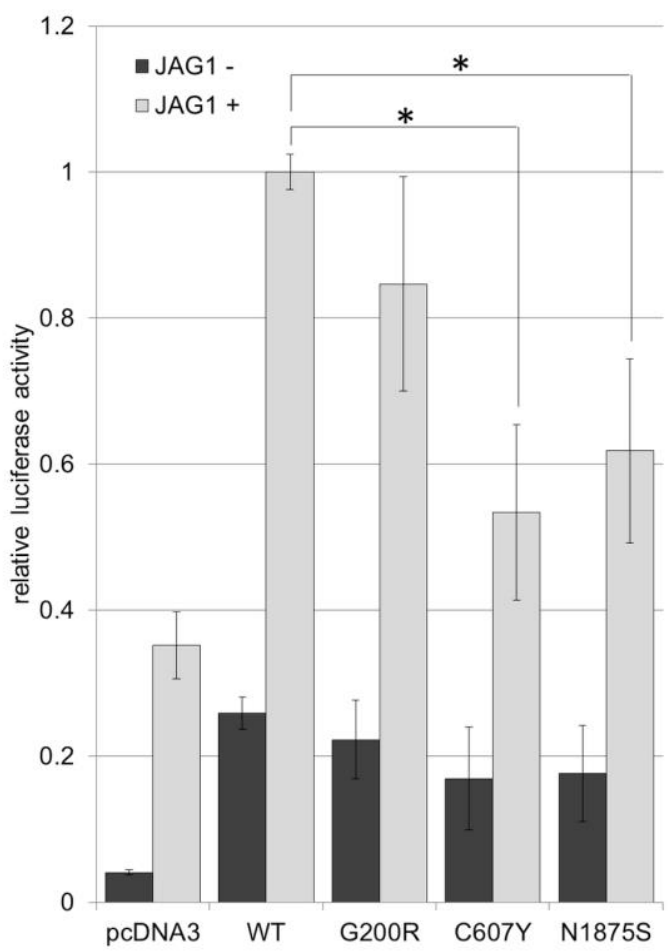

Figure 3: (a) Immunoblot for FLAG to determine the expression and cleavage of NOTCH1 variants p.G200R, p.C607Y and p.N1875S in comparison to WT NOTCH1 following overexpression in HeLa cells. The two bands at $300 \mathrm{kDa}$ (P300) and $120 \mathrm{kDa}$ (P120) represent the full length and cleaved NOTCH1 protein. $\beta$-actin was used as a loading control. (b) Quantification of the percentage of cleaved versus uncleaved NOTCH1 protein for WT NOTCH1 and NOTCH variants p.G200R, p.C607Y and p.N1875S. Error bars: mean \pm SEM from three biological replicates and statistical significance was determined using twotailed paired $t$-tests. (c) The effect of rare, deleterious NOTCH1 variants on Jagged-induced NOTCH signalling levels. NOTCH signaling activity was measured using a luciferase-based reporter system (RBPJ). HeLa cells were cultured with or without immobilised JAG1 ligand and co-transfected with RBPJ reporter constructs and WT NOTCH1, p.G200R, p.C607Y or p.N1875S. Firefly luciferase readings were normalised to Renilla luciferase readings to control for transfection efficiency and cell number. RBPJ activity was expressed relative to WT for comparison. Error bars: mean \pm SEM from four biological replicates, each with three technical replicates. Statistical significance was assessed using two-tailed paired $t$-tests. 